\title{
Quality of fixed dose artemether/ lumefantrine products in Jimma Zone, Ethiopia
}

\author{
Sileshi Belew ${ }^{1,2}$, Sultan Suleman², ${ }^{*}$ Tesfaye Mohammed ${ }^{2}$, Yimer Mekonnen², Markos Duguma², \\ Henok Teshome ${ }^{2}$, Bikila Bayisa ${ }^{4}$, Evelien Wynendaele ${ }^{1}$, Matthias D'Hondt ${ }^{1}$, Luc Duchateau ${ }^{3}$ \\ and Bart De Spiegeleer ${ }^{{ }^{*}}$
}

\begin{abstract}
Background: Malaria caused by Plasmodium vivax and Plasmodium falciparum is among the major public health problems in most endemic areas of the world. Artemisinin-based combination therapy (ACT) has been recommended as a first-line treatment for uncomplicated Plasmodium falciparum malaria almost in all endemic regions. Since ineffectively regulated medicines in resource limited settings could favour infiltration of poor quality antimalarial medicines into pharmaceutical supply chain and jeopardize a positive treatment outcome, regular monitoring of the quality of anti-malarial medicines is critical. Thus, the aim of this study was to assess the quality of fixed dose combination (FDC) artemether (ART)/lumefantrine (LUM) tablets available in Jimma zone, Ethiopia.
\end{abstract}

Methods: This study was conducted in Jimma zone, Ethiopia. A total of 74 samples of FDC ART/LUM (20 mg ART/120 mg LUM) tablets were collected from 27 public facilities. All samples were subjected to visual inspection and the relevant information was recorded. The samples were transported to Jimma University Laboratory of Drug Quality (JuLaDQ) and stored at ambient temperature $\left(20^{\circ} \mathrm{C}\right.$ to $\left.25^{\circ} \mathrm{C}\right)$ until analysis. The Pharmacopoeial conform/non-conform methods and the risk-based Derringer's desirability function approach were employed to assess the pharmaceutical quality of the investigated products.

Results: The visual inspection results revealed that there were no signs of falsified in the investigated products. Identification test results of samples indicated that all samples contained the stated active pharmaceutical ingredients (APIs). The results of uniformity of mass indicated that all samples complied with International Pharmacopoeial specification limits. The assay results, expressed as percent label claim (\%lc) of ART (89.8 to 108.8\%, mean \pm SD $=99.1 \pm 3.9 \%$ ) and LUM (90.0 to $111.9 \%$, mean \pm SD $=98.2 \pm 3.8 \%$ ) revealed that, all samples complied with International Pharmacopoeia acceptance specification limits (i.e. $90-110 \%$ lc), except one generic product (IPCA Laboratories Ltd., India) which contains excessive LUM $(111.9 \pm 1.7 \% \mathrm{lc})$. The risk priority number (RPN) results revealed that assay $(\mathrm{RPN}=392)$ is relatively the most critical quality attribute followed by identity $(R P N=280)$ and mass uniformity (40). Quality evaluation based on psycho-physical Harrington's scale revealed that more than $96 \%$ of samples were within the acceptable ranges $(D \geq 0.7-1.0)$.

Conclusions: Both Pharmacopoeial and risk-based desirability function approaches to quality evaluation applied to the investigated products revealed that above 96\% FDC ART/LUM tablets circulating in public settings of Jimma zone are of good quality.

\footnotetext{
*Correspondence: sultan.suleman@ju.edu.et; sultan.sulemanl@gmail.com;

Bart.DeSpiegeleer@UGent.be

${ }^{1}$ Drug Quality and Registration (DruQuaR) Group, Faculty

of Pharmaceutical Sciences, Ghent University, Ottergemsesteenweg 460,

9000 Ghent, Belgium

${ }^{2}$ School of Pharmacy, Jimma University, PO Box 378, Jimma, Ethiopia

Full list of author information is available at the end of the article
} 
Keywords: Quality, Anti-malarials, Artemether, Lumefantrine, Jimma, Ethiopia

\section{Background}

Malaria is the major public health problem in Africa which accounts for $90 \%$ of all malaria cases and $92 \%$ of deaths ascribed to malaria in the world [1]. Interventions such as use of anti-malarial medicines, insecticidetreated bed nets and indoor residual sprays have been employed in malaria endemic areas [2-7] and reduced malaria prevalence by $50 \%$ and clinical incidence by $40 \%$ between 2000 and 2015 [3]. However, prevalence of poor quality anti-malarial medicines [8-10] linked to reduced efficacy, treatment failure or death [11-13] and insecticide resistance of malaria transmitting mosquitoes [14, 15] are obstacles potentially threatening the global target to eliminate incidence of malaria infection [16].

In Ethiopia, malaria infection caused by Plasmodium vivax and Plasmodium falciparum is a common problem that affects a large number of people living in malariaendemic areas $[17,18]$. Thus, to reduce mortality and morbidity due to malaria, fixed dose combination (FDC) artemether (ART)/lumefantrine (LUM) and chloroquine have been used as first-line treatment for malaria caused by Plasmodium falciparum and Plasmodium vivax, respectively [19]. Since poor quality [i.e. falsified (medical products that deliberately/fraudulently misrepresent their identity, composition or source) or substandard (authorized medical products that fail to meet either their quality standards or their specifications, or both) of anti-malaria medicines is one of the risk factors that could affect the intended clinical outcomes, ensuring the quality of medicines is crucial in providing quality health care services. In Ethiopia, though there are previous studies indicating the occurrence of poor quality of anthelminthic, anti-protozoal and non artemisinin-based combination therapy (ACT) anti-malarial medicines [2024], no evidenced information is found on the quality of FDC ART/LUM products. Thus, evaluating the quality of FDC ART/LUM products circulating in the health facilities is critical to reduce risk of having poor quality medicines. Therefore, the aim of this study was to assess the pharmaceutical quality of FDC ART/LUM tablets available in Jimma zone, Oromia Regional state, Ethiopia.

\section{Methods}

\section{Study area}

The study was conducted in all districts of Jimma zone, Oromia Regional State. The areas were selected due to the fact that they are endemic for malaria. In Ethiopia, patients can get FDC ART/LUM products free of charge from public health centres and hospitals. Thus, these products are less likely to be dispensed in private drug retail outlets. Therefore, all government owned public facilities (health centre, hospitals and wholesales) operating in the study area were included in this study. Jimma is the commercial hub for the south west Ethiopia and thus relatively huge pharmaceutical transaction occurs in the region. Currently, there are 7 wholesales (all of them in Jimma city), 71 drug shops (31 in Jimma city and 40 in districts of Jimma zone), 101 public drug shops in health centres ( 3 in Jimma city and 98 in districts of Jimma zone), 18 private pharmacies (all of them in Jimma city) and 4 hospital pharmacies in Jimma zone. The map of Jimma zone, Oromia Regional State is presented in Fig. 1.

\section{Chemicals/reagents/solvents}

Artemether $(99 \% \mathrm{w} / \mathrm{w})$ and lumefantrine $(99 \% \mathrm{w} / \mathrm{w})$ working standard active pharmaceutical ingredients (APIs) were supplied by Dafra Pharma International (B-2300 Turnhout, Belgium) through Drug Quality and Registration (DruQuaR) laboratory, University of Ghent, Belgium. Ultrapure water $\left(18.2 \mathrm{M} \Omega \mathrm{cm}\right.$ at $\left.25^{\circ} \mathrm{C}\right)$ was prepared in Jimma University Laboratory of Drug Quality (JuLaDQ) using ultrapure water purification system (Thermofischer Scientific, USA). Methanol (HPLC grade, Fisher Scientific), acetonitrile (HPLC grade, Fisher Scientific), ethyl acetate and acetone (Fisher Scientific), glacial acetic acid and sulfuric acid (Reagent Chemical Services), sodium hexanesulfonate (Fluka Analytical, Germany) and sodium dihydrogen phosphate (Reagent Chemical Services) were used as received.

\section{Sample collection}

The quality survey was conducted by considering the guidelines for field surveys of the quality of medicines proposed by Newton et al. [25]. A total of 74 FDC ART/LUM (20 mg ART/120 mg LUM) tablets samples were collected between May and June, 2013 from all public health facilities (where available) [wholesales $(n=2)$, hospital pharmacy $(n=1)$ and health centre drug stores $(n=24)$ ] operation in Jimma zone. Sample with different products names (i.e. Coartem ${ }^{\circledR}=35$ and generic $=39$ ) and countries of origin [Ethiopia $(\mathrm{n}=1)$, China $(\mathrm{n}=1)$, India $(\mathrm{n}=38)$ and USA $(\mathrm{n}=34)$ ] were collected anonymously by mystery shoppers from local area who were trained before to present a confirmed P. falciparum malaria patient of 25 years of age with a prescription stating 4 tablets twice per day for 3 consecutive days (full adult dose of 24 tablets). The mystery shoppers were blinded about the purpose of 




Fig. 1 Map of Jimma zone, Oromia Regional State

the study and only instructed to collect samples. The relevant information of all collected samples (level of drug outlet, place of collection, name of APIs, country of origin, manufacturing company, expiry date, manufacturing date, batch/lot number and strength of APIs) was recorded on standard form as soon as leaving the drug outlet and entered into database. The samples were transported to JuLaDQ and stored at ambient temperature $\left(20^{\circ} \mathrm{C}\right.$ to $\left.25^{\circ} \mathrm{C}\right)$ until analysis.

\section{Physico-chemical quality assessment}

All samples were visually inspected for physical characteristics of tablets (i.e. shapes, colour, breaks, cracks and splits), packaging and labelling information (i.e. name of the active pharmaceutical ingredient, the country of origin, manufacturing company, expiry date, manufacturing date, batch/lot number, number of units per strip/package and labelled dose (strength) of the active ingredient) using the checklist set by WHO [26]. The modified checklist is presented in Additional file 1.

\section{Identification tests}

The presence of ART and LUM APIs in FDC ART/LUM tablets was analysed according to the method given in the International Pharmacopoeia [27]. In addition, thin layer chromatography, chromatographic peak retention time and DAD-UV absorption spectra were used for the purpose of identification through comparison with retention time and DAD-UV absorption spectra of the peak obtained on a working standard solutions of ART and LUM APIs.

\section{Uniformity of mass}

The mass uniformity test of tablet samples was conducted according to the method given in the International Pharmacopoeia [28]. Randomly selected tablets $(n=20)$ of each sample were individually weighed with a calibrated balance (Mettler Toledo, AL204-1C, Switzerland) with an accuracy of $0.006 \%$. The uniformity of mass of the tablet samples was evaluated against Pharmacopoeial specification (i.e. the deviation of individual masses of minimum of 18 and maximum of 2 tablets should not exceed by $\pm 7.5 \%$ and $\pm 15 \%$ from average mass, respectively). 
Assay of active substance in the tablet samples

The amount of ART and LUM APIs in samples of FDC ART/LUM tablets was determined based on the method given in an individual monograph of International Pharmacopoeia [29].

\section{System suitability}

System suitability was evaluated according to the European Pharmacopoeia method [30]. The symmetry factor $\left(\mathrm{A}_{\mathrm{s}}\right)$ of principal peaks was calculated using the following formula:

$$
A s=W_{x} / 2 d
$$

where $\mathrm{W}_{\mathrm{x}}=$ peak width at $5 \%$ of reference standard peak height measured from the base line, $d=$ base line distance between the perpendicular dropped from the peak maximum and the leading edge of the peak at $5 \%$ of peak height measured in the same unit as $\mathrm{W}_{\mathrm{x}}$. The specification was an $\mathrm{A}_{\mathrm{s}}$ value of maximally 1.5. In addition, percent relative standard deviation (\%RSD) of replicate injections $(n=6)$ of reference standards were calculated and compared against the European Pharmacopoeia specification limit, i.e. \%RSD of sextuplicate injections should be maximally 2 .

\section{Mobile phase preparation}

The mobile phases 70/30\% v/v (A) and 30/70\% v/v (B) ion pair reagent/acetonitrile (HPLC grade, Fisher Scientific) were prepared for gradient elution. Ion-pair reagent was prepared by dissolving $5.65 \mathrm{~g}$ of sodium hexanesulfonate (Fluka Chemicals Ltd.) and $2.75 \mathrm{~g}$ of sodium dihydrogen phosphate (Fishers Scientific) in $900.0 \mathrm{ml}$ of ultra-pure water $(18.2 \mathrm{M} \Omega \mathrm{cm})$ and adjusted to $\mathrm{pH} 2.3$ using phosphoric acid (ReAgent Chemicals, UK), diluted to volume $(1000.0 \mathrm{ml})$ and filtered through a $0.45 \mu \mathrm{m}$ filter (Macherey-Nagel, Germany).

\section{Working standard solution}

Working standards of ART (20 mg) and LUM (120 mg) were individually added into $100.0 \mathrm{ml}$ volumetric flask, dissolved in $85 \mathrm{ml}$ of solvent (i.e. ion pair/ultra-pure water/1-propanol/acetonitrile: 20/6/20/54\% v/v), sonicated, allowed to cool to room temperature and diluted to volume.

\section{Sample solution}

Twenty tablets of each sample were randomly selected and powdered. A portion of powder equivalent to $20 \mathrm{mg}$ ART and $120 \mathrm{mg}$ LUM was individually added into $100.0 \mathrm{ml}$ volumetric flask, dissolved in $85.0 \mathrm{ml}$ of solvent (i.e. ion-pair/ultra-pure water/1-propanol/ acetonitrile: $20 / 6 / 20 / 54 \% \mathrm{v} / \mathrm{v}$ ), sonicated (20 $\mathrm{min})$, allowed to cool to room temperature and diluted to volume.

\section{HPLC method}

The analysis of samples was conducted using Agilent 1260 Infinity Series HPLC system (Agilent Technologies, Santa Clara, California, USA) equipped with a C18 column (Symmetry $\left.{ }^{\circledR}\right)(150 \mathrm{~mm} \times 3.9 \mathrm{~mm}, 5 \mu$ particle size) coupled to a diode-array detector (DAD). The sample temperature in auto-injector was $25^{\circ} \mathrm{C}$. The column temperature, flow rate, injection volume, run time were $25^{\circ} \mathrm{C}, 1.3 \mathrm{ml} / \mathrm{min}, 20 \mu \mathrm{l}$ and $55 \mathrm{~min}$, respectively.

\section{Risk analysis}

Failure mode effects analysis (FMEA) was used to evaluate criticality of product quality attributes. Criticality was evaluated based on risk priority number (RPN) which considered occurrence, severity and detection of the failure and calculated using the formula:

$$
R P N=O \times S \times D
$$

where $\mathrm{O}, \mathrm{S}$ and $\mathrm{D}$ denote the occurrence of a failure mode, the severity of a failure effect, and the probability of not detecting the failure, respectively [31].

The scales used for scoring severity, occurrence and detectability are presented in Tables 1, 2, 3.

Pharmaceutical experts working at JuLaDQ $(n=3)$ and Ethiopian Food and Drug Authority (EFDA) $(n=2)$ were assigned to score for severity, occurrence and detectability. The potential effect of each failure mode

\begin{tabular}{|c|c|c|}
\hline Probability of failure & Possibility of failure rates & Rank \\
\hline $\begin{array}{l}\text { Extremely high: failure } \\
\text { almost inevitable }\end{array}$ & $\geq 1$ in 2 & 10 \\
\hline Very high & 1 in 3 & 9 \\
\hline Repeated failures & 1 in 8 & 8 \\
\hline High & 1 in 20 & 7 \\
\hline Moderately high & 1 in 80 & 6 \\
\hline Moderate & 1 in 400 & 5 \\
\hline Relatively low & 1 in 2000 & 4 \\
\hline Low & 1 in 15,000 & 3 \\
\hline Remote & 1 in 150,000 & 2 \\
\hline Nearly impossible & $\leq 1$ in $1,500,00$ & 1 \\
\hline
\end{tabular}
was considered to assign a severity rating. Thus, the 
Table 2 Traditional FMEA scale for severity. Source: Ford Motor Company. Potential Failure Mode and Effects Analysis (FMEA) Reference Manual; Ford Motor Company: Dearborn, MI, USA, 1988. https://www.worldcat.org/title/potential-failu re-mode-and-effects-analysis-fmea-reference-manual/oclc/43210773

\begin{tabular}{llr}
\hline Effect & Criteria: severity of effect & Rank \\
\hline Hazardous & Failure is hazardous, and occurs without warning. It suspends operation of the system & 10 \\
Serious & Failure involves hazardous outcomes and/or noncompliance with government regulations or standards & 9 \\
Extreme & Product is inoperable with loss of primary function. The system is inoperable & 8 \\
Major & Product performance is severely affected but functions. The system may not operate & 7 \\
Significant & Product performance is degraded. Comfort or convince functions may not operate \\
Moderate & Moderate effect on product performance. The product requires repair & 6 \\
Low & Small effect on product performance. The product does not require repair & 5 \\
Minor & Minor effect on product or system performance & 3 \\
Very minor & Very minor effect on product or system performance & 2 \\
None & No effect & 1 \\
\hline
\end{tabular}

Table 3 Traditional FMEA scale for detection. Source: Ford Motor Company. Potential Failure Mode and Effects Analysis (FMEA) Reference Manual; Ford Motor Company: Dearborn, MI, USA, 1988. https://www.worldcat.org/title/potential-failu re-mode-and-effects-analysis-fmea-reference-manual/oclc/43210773

\begin{tabular}{ll}
\hline Detection & Criteria: likelihood of detection by design control \\
\hline $\begin{array}{l}\text { Absolute uncertainty } \\
\text { Very remote }\end{array}$ & Design control does not detect a potential cause of failure or subsequent failure mode; or there is no design control \\
Remote & Remote chance the design control will detect a potential cause of failure or subsequent failure mode \\
Very low & Very low chance the design control will detect a potential cause of failure or subsequent failure mode \\
Low & Low chance the design control will detect a potential cause of failure or subsequent failure mode \\
Moderate & Moderate chance the design control will detect a potential cause of failure or subsequent failure mode \\
Moderately high & Moderately high chance the design control will detect a potential cause of failure or subsequent failure mode \\
High & High chance the design control will detect a potential cause of failure or subsequent failure mode \\
Very high & Very high chance the design control will detect a potential cause of failure or subsequent failure mode \\
Almost certain & Design control will almost certainly detect a potential cause of failure or subsequent failure mode
\end{tabular}$\quad$\begin{tabular}{l}
5 \\
\hline
\end{tabular}

score of 10, 8 and 5 was assigned for identity, assay and mass uniformity, respectively. Literature data on prevalence of substandard and/or falsified anti-malarial medicines in Africa [8-10,32] and the findings from this study were used to assign scores for occurrence. Therefore, the occurrence score of 7, 7 and 4 were assigned for identity, assay and uniformity of mass, respectively. Detecting defects of the mass uniformity and identity is relatively easy and does not require high technology facility, advanced knowledge and skills. Therefore, detectability score of 4 and 2 was assigned for identity and mass uniformity, respectively. On the other hand, since assay requires fully equipped laboratory system and advanced training of personnel, detectability score of 7 was assigned for assay. The assigned scores for severity, occurrence and detectability are presented in Additional file 2.

\section{Desirability function}

Derringer's desirability function [23,33] was applied to assess quality of the evaluated product. The overall desirability function (D) value which is the geometric mean of the individual desirabilities $\left(\mathrm{d}_{\mathrm{i}}\right)$, indicates the product quality. The highest global desirability value represents the product with the highest quality. The $\mathrm{D}$ value was calculated using the following formula:

$$
\sqrt[n]{\prod_{i=1}^{n} d_{i}^{p_{i}}}
$$

where $p_{i}$ is the weight or relative importance assigned to the response, $\mathrm{n}$ is the product quality attributes evaluated, $d_{i}$ is an individual desirability. In this study, three product quality attributes (i.e. identity, assay and mass uniformity) were considered and thus n equals to 3 is 
taken in global evaluation of the investigated FDC ART/ LUM tablet samples. According to RPN value, which is the numeric assessment of risk assigned to each quality parameter, $p$ value of 3, 2 and 1 was assigned for assay, identity and mass uniformity, respectively.

Modified psychophysical five interval scale of Harrington's desirability function [34] was constructed and used as a tool for quality judgment; i.e. qualitative assessments "bad", "low", "acceptable", "good" and "excellent" which correspond to numeric intervals of $0.00-0.37$, $0.37-0.70,0.70-0.80,0.80-0.90$, and $0.90-1.00$, respectively. The numeric desirability values of the quality attributes were considered as physical parameters; while the subjective judgments of the experts (i.e. excellent, good, acceptable, low or bad) were considered as psychological. For assay a two-sided desirability function was used; and a one-sided desirability function was used for identity and mass uniformity. Since absence of API is assumed to be clinically completely undesirable, $d=0$ was assigned. While $\mathrm{d}=1$ was assigned for $100 \%$ lc which is assumed to be optimum desirability. Since assay of both ART and LUM APIs in FDC ART/LMU tablet should be from 90 to $110 \%$ lc [29] and psychophysical Harrington's scale specifies desirability range from 0.70 to 1.00 to be good, $\mathrm{d}=0.7$ was assigned for assay values of 90 and $110 \%$ lc and $d=0.3$ was assigned for $70 \%$ and $130 \%$ lc. While $d=0.01$ was assigned for $50 \%$ and $150 \%$ lc. The individual desirability function for assay was then defined as different linear sections of different slopes in the range of $100 \%$ lc to $90 \%$ lc (slope $=0.03$ ), $90 \%$ lc to $70 \%$ lc (slope $=0.02)$ and from $70 \%$ lc to $50 \%$ lc (slope $=0.01)$.

For mass uniformity, the relative standard deviation (RSD) was considered as response. According to European Pharmacopoeia [28], RSD should not be more than $2 \%$ and thus $\mathrm{d}=1, \mathrm{~d}=0.7, \mathrm{~d}=0.3, \mathrm{~d}=0.01$ and $\mathrm{d}=0$ were assigned for RSD of $0,2,6,15$ and $25 \%$, respectively. For identity, $\mathrm{d}=1.0$ was assigned for samples complied with Pharmacopoeia specification. While $d=0$ was assigned for those which do not comply.

\section{Results}

A total of 74 samples (i.e. Coartem ${ }^{\circledR}=35$, $\operatorname{Artefan}^{\circledR}=6$, Artemine ${ }^{\circledR}=1$, and artemether-lumefantrine $=32$ ) were collected between May to June, 2013 from wholesales $(\mathrm{n}=2)$, hospitals $(\mathrm{n}=4)$ and health centres $(\mathrm{n}=68)$.

The results of visual inspection of samples for physical characteristics of tablets, packaging and labelling information as set by WHO revealed that there were no signs of falsified in the investigated products. Detail information of samples on physical characteristics of tablets, packaging and labelling information is presented in Additional file 3.
Identification test results of samples revealed that all samples had the intended APIs as demonstrated by the positive identification tests. Consistent results were obtained with the Pharmacopoieal methods, thin-layer chromatography, HPLC retention and DAD information.

The results of uniformity of mass indicated that all samples complied with International Pharmacopoeia specification limits (i.e. the deviation of individual masses of minimum of 18 and maximum of 2 tablets should not exceed by $\pm 7.5 \%$ and $\pm 15 \%$ from average mass, respectively). The mass \%deviation distributed among brand products are presented in Table 4.

The results of amount of ART and LUM in the FDC ART/LUM tablet samples revealed that except one generic product (IPCA Laboratories Ltd., India) which failed to comply (111.9\%lc) for LUM API, all samples complied with the Pharmacopoieal acceptance specification limit [i.e. 90.0-110.0\% (percent label claim (\%lc)]. The amount of ART API in samples analysed ranges from 89.8 to $108.8 \%$ (mean: $99.1 \%$, SD: $3.9 \%$ ), while that of LUM ranges from 90.0 to $111.9 \%$ (mean: $98.2 \%$, SD: 3.8\%). The amount of ART and LUM APIs in FDC ART/LUM tablet samples collected from health centre $(\mathrm{ART}=89.78-105.92 \%, \quad \mathrm{LUM}=91.19-111.87 \%)$, hospitals $\quad($ ART $=97.70-101.94 \%, \quad L U M=90.03-104.24 \%)$ and wholesales (ART $=100.52-108.78 \%, \mathrm{LUM}=93.68-$ $107.98 \%$ ) indicated relative differences in the amount of ART/LUM APIs among investigated products. The results of the amount (\%lc) of ART and LUM APIs in FDC ART/LUM tablet samples are presented in Additional file 4. Amount (\%lc) of ART and LUM APIs distributed among brand and generic product is given in Table 5.

\section{Risk analysis}

The results of the RPN are presented in Table 6. Assay $(\mathrm{RPN}=392)$ is the most critical quality attribute followed by identity $(\mathrm{RPN}=280)$ and mass uniformity $(\mathrm{RPN}=40)$.

\section{Derringer's desirability function}

The results of individual desirability values $\left(\mathrm{d}_{\mathrm{i}}\right)$ and the overall desirability (D) are presented in Additional file 5 .

\begin{tabular}{|c|c|c|c|c|}
\hline \multirow[t]{2}{*}{$\#$} & \multirow[t]{2}{*}{ Product name $(n)$} & \multicolumn{3}{|c|}{ \%Deviation } \\
\hline & & Minimum & Maximum & Mean \\
\hline 1 & Coartem ${ }^{\circledR}(35)$ & 0.75 & 7.11 & 1.61 \\
\hline 2 & Artemether-lumefantrine (32) & 0.80 & 2.64 & 1.78 \\
\hline 3 & $\operatorname{Artefan}^{\circledR}(6)$ & 0.99 & 4.5 & 2.55 \\
\hline 4 & Artemine $^{\circledR}(1)$ & 1.34 & 1.34 & 1.34 \\
\hline
\end{tabular}


Table 5 Amount (\%Ic) of ART and LUM APIs distributed among brand and generic products

\begin{tabular}{|c|c|c|c|c|c|c|c|}
\hline \multirow[t]{2}{*}{$\#$} & \multirow[t]{2}{*}{ Product name (n) } & \multirow[t]{2}{*}{ API } & \multicolumn{5}{|l|}{ \%lc } \\
\hline & & & Minimum & Maximum & Mean & SD & Median \\
\hline \multirow[t]{2}{*}{1} & \multirow[t]{2}{*}{ Coartem $^{\circledR}(35)$} & ART & 90.9 & 103.6 & 98.9 & 3.0 & 99.6 \\
\hline & & LUM & 90.0 & 104.1 & 97.4 & 3.4 & 97.7 \\
\hline \multirow[t]{2}{*}{2} & \multirow[t]{2}{*}{ Artemether-lumefantrine (32) } & ART & 91.5 & 106.7 & 99.2 & 4.3 & 99.7 \\
\hline & & LUM & 93.6 & 111.9 & 98.8 & 3.8 & 98.7 \\
\hline \multirow[t]{2}{*}{3} & \multirow[t]{2}{*}{$\operatorname{Artefan}^{\circledR}(6)$} & ART & 89.8 & 103.4 & 98.2 & 5.0 & 99.4 \\
\hline & & LUM & 91.2 & 104.2 & 98.7 & 4.7 & 99.6 \\
\hline \multirow[t]{2}{*}{4} & \multirow[t]{2}{*}{ Artemine ${ }^{\circledR}(1)$} & ART & 108.8 & 108.8 & 108.8 & NA & 108.8 \\
\hline & & LUM & 108.0 & 108.0 & 108.0 & NA & 108.0 \\
\hline
\end{tabular}

SD standard deviation, NA not applicable

Table 6 Failure mode and effect analysis for FDC ART/LUM tablet quality attributes

\begin{tabular}{|c|c|c|c|c|c|c|}
\hline Critical quality attributes & Failure mode & Failure effects & Severity & Occurrence & Detection & RPN \\
\hline Identity & $\begin{array}{l}\text { No (intended) active ingredient in the } \\
\text { sample or mislabelling (incorrect, } \\
\text { inadequate or incomplete identi- } \\
\text { fication) }\end{array}$ & $\begin{array}{l}\text { Treatment failure, death due to } \\
\text { untreated disease, toxicity }\end{array}$ & 10 & 7 & 4 & 280 \\
\hline Assay & Under-dose, over-dose & $\begin{array}{l}\text { Treatment failure, toxicity due to } \\
\text { over-dose, drug resistance due to } \\
\text { under-dose }\end{array}$ & 8 & 7 & 7 & 392 \\
\hline Uniformity of mass & $\begin{array}{l}\text { Non-uniform distribution of dose/ } \\
\text { content within the individual dos- } \\
\text { age units }\end{array}$ & $\begin{array}{l}\text { Sub-optimal therapy for a patient tak- } \\
\text { ing the sub-standard dosage unit } \\
\text { and drug resistance }\end{array}$ & 5 & 4 & 2 & 40 \\
\hline
\end{tabular}

$R P N$ risk priority number

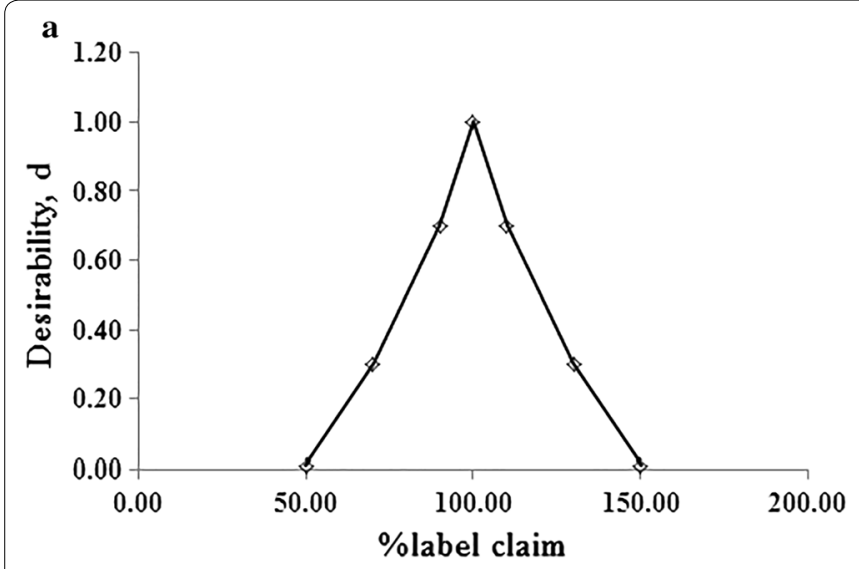

Fig. 2 Linear desirability functions: a assay and $\mathbf{b}$ mass uniformity

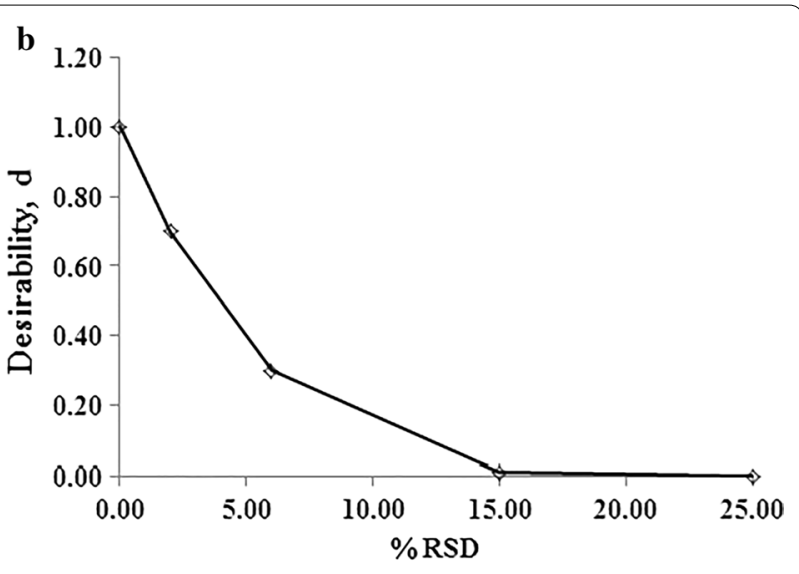

The individual desirability values assigned to the different segments were fitted to the segmented linear model as presented in Fig. 2.

A global D-value of investigated products was calculated using d-functions of quality attributes (i.e. identity, assay and mass uniformity). Since FDC ART/ LUM tablet contains FDC $20 \mathrm{mg}$ ART and $120 \mathrm{mg}$ LUM APIs, d-functions of identity and assay for ART and LUM were calculated individually. Based on Harrington's scale of quality, $96 \%$ of the investigated products were within acceptable range $(D=0.7-1.0)$. The 


\begin{tabular}{|c|c|c|c|}
\hline \# & $\begin{array}{l}\text { Interval in global } \\
\text { desirability }\end{array}$ & $\begin{array}{l}\text { Quality, } \\
\text { descriptive } \\
\text { evaluation }\end{array}$ & $\begin{array}{l}\text { Percent of products } \\
\text { in each quality scale }\end{array}$ \\
\hline
\end{tabular}

\begin{tabular}{|c|c|c|c|}
\hline \multicolumn{4}{|c|}{ ART in FDC ART/LUM tablets } \\
\hline 1 & $0.90-1.00$ & Excellent & 47.3 \\
\hline 2 & $0.80-0.90$ & Good & 31.1 \\
\hline 3 & $0.70-0.80$ & Acceptable & 20.3 \\
\hline 4 & $0.37-0.70$ & Low & 1.4 \\
\hline 5 & $0.00-0.37$ & Bad & - \\
\hline \multicolumn{4}{|c|}{ LUM in FDC ART/LUM tablets } \\
\hline 1 & $0.90-1.00$ & Excellent & 39.2 \\
\hline 2 & $0.80-0.90$ & Good & 36.5 \\
\hline 3 & $0.70-0.80$ & Acceptable & 20.3 \\
\hline 4 & $0.37-0.70$ & Low & 4.1 \\
\hline 5 & $0.00-0.37$ & Bad & - \\
\hline
\end{tabular}

results of quality evaluation based on modified psychophysical Harrington's scale of quality are presented in Table 7.

\section{Discussion}

In this study, the pharmaceutical quality of FDC ART/ LUM tablets was assessed. The results of visual inspection on physical characteristics of tablets, packaging and labelling information revealed that none of the samples demonstrated signs of falsified as defined by the WHO [35]. In addition, packaging of the investigated products complied with the WHO guideline on packaging for pharmaceutical products [36]. Appropriate packaging is important to protect the pharmaceutical products from environmental and transportation stress which are risk factors for product quality defects. Thus, the investigated products might not have a risk of stability problems associated with packaging [37].

The identity test results indicated that none of the samples contained incorrect APIs which revealed that due to the investigated products there was no risk of treatment failures or death [38-40]. The study results indicated that the investigated products complied with mass uniformity specification set in International Pharmacopoiea for uncoated and film-coated tablets formulated to contain $5 \%$ or more of the active ingredient (i.e. the deviation of individual masses of minimum of 18 and maximum of 2 tablets should not exceed by $\pm 7.5 \%$ and $\pm 15 \%$ from average mass, respectively) [28]. This suggests that variations observed in mass among dose units in each batch might not affect the content uniformity of the dose units of the investigated products as mass uniformity is an alternative test for content uniformity of uncoated and film coated tablets.

The results of amount of APIs indicated that majority (98.6\%) of investigated products comply with Pharmacopoeial specification limit (i.e. \%lc $=90-110 \%$ ) [29]. Only one generic product contain excess LUM API (111.7\%lc) and thus failed to comply with International Pharmacopoeia (Ph. Int.) specification. The results of amount of APIs suggest that the dose units of majority of the investigated products contain sufficient levels of both ART and LUM APIs and could not have a risk of treatment failure [12, 40-42], longer parasite clearance time and greater recrudescence $[43,44]$ and emergence of resistance [13]. Though effectiveness of medicines depends on various factors such as food intake, age, nutritional status, pharmacokinetic and IC50 of parasites [45, 46], sufficient amount of ART and LUM APIs observed in majority of the investigated products is very critical to reduce asexual parasite mass, eliminate the residual parasites and prevent recrudescence [47] and augment the recommended parasitological and clinical cure rate ( $\geq 90 \%$ ) [48] The presence of excess LUM API (111.7\%lc) in one generic product having the same batch number with the products which contain LUM API ranging from 96.1 to $102.0 \%$ lc could be attributed to excipient particle size, blending techniques or processing parameters that could influence product quality [49]. This points to poor adherence to Good Manufacturing Practice (GMP).

According to the WHO, multisource products must satisfy the same standards of quality, safety and efficacy applied to the corresponding innovator product [50]. In this study, majority of investigated products qualify Pharmacopoeial specification limits set for amount of API. Thus, interchangeable use of these products may not have a risk arising from amount of APIs.

The use of poor quality anti-malarial medicines could have a risk of reduced efficacy, an increased development of drug resistance, prolonged and more severe illness or unexpected adverse effects [11, 12, 32, 42, 43, 51]. Therefore, evaluating criticality of product quality attributes for efficacy using risk analysis method is crucial for risk mitigation strategies. To this end, failure mode effects analysis (FMEA) method [52] was used and the risk associated with each failure mode (identity, assay or mass uniformity) was evaluated based on the values of RPN. As a result, assay $(\mathrm{RPN}=392)$ is found to be the most critical quality attribute followed by identity $(\mathrm{RPN}=280)$ and mass uniformity $(\mathrm{RPN}=40)$. This implies that quality risk with regard to assay is relatively higher.

Compared to conventional (Pharmacopoieal) method of quality verification, risk-based desirability function approach to quality evaluation provides more weight to the clinically more critical quality attributes. For 
products having various quality characteristics, the quality of the product is completely unacceptable if one of the characteristics lies outside the desired limits. In this study, the quality of investigated products was evaluated based on calculated D values compared against constructed numeric intervals ranging between 0 and 1 . Thus, qualitative assessments of the investigated products (bad, low, acceptable, good and excellent) which correspond to respective numeric intervals were conducted based on modified psycho-physical Harrington's scale of quality. Based on the results obtained from risk based desirability approach of quality evaluation and considering ART and LUM APIs, $96 \%$ and $98.7 \%$ of the quality of the investigated products lie within acceptable range $(0.70-1.00)$, respectively. The results of risk-based desirability approach quality evaluation are in-line with the results (98\%) observed in Pharmacopoeial (conform/ non conform) quality verification approach. Since using of risk based desirability approach provides more weight to clinically more critical quality attributes, this approach helps to make reliable decision based on clinically more critical quality attributes. In addition, it could be used to determine deviations from the desired response levels. Moreover, risk based desirability approach of quality evaluation less heavily penalize marginal out-of specification medicines and assumed to save economic loss in resource scarce society.

\section{Conclusions}

The results of this finding revealed that the quality of 96-98\% of the investigated products lies within acceptance limit when evaluated using both Pharmacopoeial and risk-based desirability function approaches. This suggests that the medicines circulating in the public settings of Jimma zone are of good quality. However, this does not necessarily mean that there is effective regulatory system that helps to prevent infiltration of poor quality medicines into pharmaceutical supply chain. Therefore, complete nationwide survey which includes private settings should be done.

\section{Additional files} Additional file 1. Checklist. Physical characteristics, packaging and label-
ling information.

Additional file 2. Assigned scores for each factor of failure modes.

Additional file 3. Physical characteristics, packaging and labelling information.

Additional file 4. Results of the amount of ART/LUM in FDC tablets.

Additional file 5. Desirability function values.

\section{Abbreviations}

ART: artemether; LUM: lumefantrine; FDC: fixed dose combination; ACT: artemisinin-based combination therapy; WHO: World Health Organization; $\mathrm{ICH}$ : The International Conference on Harmonization.

\section{Acknowledgements}

Authors would like to thank all health centres of Jimma Zone, Jimma Specialized Hospital, and Pharmaceutical Fund and Supply Agency (PFSA) of Jimma branch whole sale for their collaboration during sample collection. In addition, we are grateful for the financial support of the Flemesh Interuniversity Council-University Development Cooperation and Directorate General for Development. Moreover, we appreciate staffs of Jimma University Laboratory of Drug Quality (JuLaDQ) and Dr. Melkamu Dumesa for their contribution.

\section{Authors' contributions}

$B D S, M D, E W, L D, S S$ and SB contributed to the conception and design of the experiment. SB, SS, MD and EW performed the experiments. BDS, LD, SB, EW and TM analysed the data. BDS, MD, LD, SS, HT, MD and YM contributed reagents/materials/analysis tools. BDS, MD, EW, LD, SS, SB and YM wrote the paper. All authors read and approved the final manuscript.

\section{Funding}

This work was financed by the Flemesh Interuniversity Council-University Development Cooperation and Directorate General for Development, Belgium. The sponsor does not have a role in decision to publish or preparation of the manuscript.

\section{Availability of data and materials}

The datasets used and/or analysed during the current study are available from the corresponding author on reasonable request.

Ethics approval and consent to participate

Not applicable.

\section{Consent for publication}

Not applicable.

\section{Competing interests}

The authors declare that they have no competing interests.

\section{Author details}

${ }^{1}$ Drug Quality and Registration (DruQuaR) Group, Faculty of Pharmaceutical Sciences, Ghent University, Ottergemsesteenweg 460, 9000 Ghent, Belgium. ${ }^{2}$ School of Pharmacy, Jimma University, PO Box 378, Jimma, Ethiopia. ${ }^{3}$ Biometrics Research Group, Faculty of Veterinary Medicine, Ghent University, Salisburylaan 133, 9820 Merelbeke, Belgium. ${ }^{4}$ Ethiopian Food and Drug Authority (EFDA), Addis Ababa, Ethiopia.

Received: 11 April 2019 Accepted: 6 July 2019

Published online: 15 July 2019

\section{References}

1. WHO. World malaria report 2016. Geneva: World Health Organization; 2017. http://www.who.int/malaria/media/world-malaria-report-2017/en/. Accessed 17 Feb 2019.

2. Abeku TA, Helinski ME, Kirby MJ, Kefyalew T, Awano T, Batisso E, et al. Monitoring changes in malaria epidemiology and effectiveness of interventions in Ethiopia and Uganda: beyond Garki project baseline survey. Malar J. 2015:14:337.

3. Bhatt S, Weiss D, Cameron E, Bisanzio D, Mappin B, Dalrymple U, et al. The effect of malaria control on Plasmodium falciparum in Africa between 2000 and 2015. Nature. 2015;526:207-11.

4. Abebe A, Yohannes N, Nigatu K. Distribution and utilization of vector control strategies in a malarious village of Jabi Tehnan district, north-western Ethiopia. Malar J. 2014;13:356.

5. Aregawi M, Lynch M, Bekele W, Kebede H, Jima D, Taffese HS, et al. Time series analysis of trends in malaria cases and deaths at hospitals and the effect of antimalarial interventions, 2001-2011, Ethiopia. PLoS ONE. 2014;9:e106359. 
6. Laith Y, Rebecca D, Guiyun Y. Indoor residual spray and insecticide-treated bednets for malaria control: theoretical synergisms and antagonisms. J R Soc Interface. 2011:8:799-806.

7. Eisele TP, Larsen D, Steketee RW. Protective efficacy of interventions for preventing malaria mortality in children in Plasmodium falciparum endemic areas. Int J Epidemiol. 2010;39(Suppl 1):88-101.

8. Kaur H, Clarke S, Lalani M, Phanouvong S, Guérin P, McLoughlin A, et al. Fake anti-malarials: start with the facts. Malar J. 2016;15:86.

9. Tabernero P, Fernández FM, Green M, Guérin PJ, Newton PN. Mind the gaps - the epidemiology of poor-quality anti-malarials in the malarious world — analysis of the WorldWide Antimalarial Resistance Network database. Malar J. 2014;13:139.

10. Nyyar G, Newton P, Herrington J. Poor-quality antimalarial drugs in southeast Asia and sub-Saharan Africa. Lancet Infect Dis. 2012;12:488-96.

11. Renschler JP, Walters KM, Newton PN, Laxminarayan R. Estimated underfive deaths associated with poor-quality antimalarials in sub-Saharan Africa. Am J Trop Med Hyg. 2015;92(Suppl 6):119-26.

12. Chaccour CJ, Kaur H, Mabey D, Del Pozo JL. Travel and fake artesunate: a risky business. Lancet. 2012;380:1120.

13. White NJ, Pongtavornpinyo W, Maude RJ, Saralamba S, Aguas R, Stepniewska K, et al. Hyperparasitaemia and low dosing are an important source of anti-malarial drug resistance. Malar J. 2009;8:253.

14. Etang J, Nwane P, Piameu M, Manga B, Souop D, Awono-Ambene P. Evaluation of new tools for malaria vector control in Cameroon: focus on long lasting insecticidal nets. PLoS ONE. 2013;8:e74929.

15. Abdalla H, Wilding CS, Nardini L, Pignatelli P, Koekemoer LL, Ranson H, et al. Insecticide resistance in Anopheles arabiensis in Sudan: temporal trends and underlying mechanisms. Parasit Vectors. 2014;7:213.

16. WHO. Eliminating malaria. Geneva: World Health Organization; 2016 http://apps.who.int/iris/bitstream/handle/10665/205565/WHO_HTM_ GMP_2016.3_eng.pdf. Accessed 20 Feb 2019.

17. Frew T, Andrew WF, Wakgari D. Prevalence and associated risk factors of malaria among adults in East Shewa zone of Oromia Regional State Ethiopia: a cross-sectional study. BMC Public Health. 2018;18:25.

18. Deribew A, Tessema GA, Deribe K, Melaku YA, Lakew Y, Amare AT, et al. Trends, causes, and risk factors of mortality among children under 5 in Ethiopia, 1990-2013: findings from the Global Burden of Disease Study 2013. Popul Health Metr. 2016;14:42.

19. Federal Ministry of Health (FMoH). Guideline for malaria epidemic prevention and control in Ethiopia. Addis Ababa: Federal Democratic Republic of Ethiopia; 2012. https://www.medbox.org/national-malar ia-guidelines-ethiopia/download.pdf. Accessed 10 Feb 2019.

20. Tekle T, Terefe G, Cherenet T, Ashenafi KG, Akoda AT, Teko-Agbo A, et al. Aberrant use and poor quality of trypanocides: a risk for drug resistance in south western Ethiopia. BMC Vet Res. 2018;14:4.

21. Belew S, Getachew M, Suleman S, Mohammed T, Deti H, D'Hondt M, et al. Assessment of efficacy and quality of two albendazole brands commonly used against soil-transmitted helminth infections in school children in Jimma town, Ethiopia. PLoS Negl Trop Dis. 2015;9:0004057.

22. Belew S, Suleman S, Wynendaele E, D'Hondt M, Kosgei A, Duchateau L, et al. Quality of anthelminthic medicines available in Jimma Ethiopia. Acta Trop. 2018;177:157-63.

23. Suleman S, Zeleke G, Deti H, Mekonnen Z, Duchateau L, Levecke B, et al. Quality of medicines commonly used in the treatment of soil transmitted helminths and giardia in Ethiopia: a nationwide survey. PLoS Negl Trop Dis. 2014;8:e3345

24. WHO. Survey of the quality of selected anti-malarial medicines circulating in six countries of sub-Saharan Africa. Quality assurance and safety: medicines essential medicines and pharmaceutical policies. Geneva: World Health Organization; 2011. http://www.who.int/medicines/publications/ WHO_QAMSA_report.pdf. Accessed 12 Mar 2013.

25. Newton PN, Lee SJ, Goodman C, Fernández FM, Yeung S, Phanouvong S, et al. Guidelines for field surveys of the quality of medicines: a proposal. PLoS Med. 2009;6:e1000052

26. WHO. Tool for visual inspection of medicines. A checklist for visual inspection of medicines in order to identify suspicious products for further examination. Geneva: World Health Organization; 2015. http://www. whpa.org/toolkit_beaware_inspection.pdf. Accessed 12 Mar 2013.

27. WHO. The International Pharmacopoeia, 5th edition. Monographs: dosage forms: specific monographs: artemether and lumefantrine tablets.
1.14.1 Thin-layer chromatography. Geneva: World Health Organization. http://apps.who.int/phint/en/p/docf/. Accessed 18 Feb 2013.

28. European Pharmacopoeia, 8th edition. Chapter 2.9.5. Uniformity of mass of single dose preparations. European Directorate for Quality of Medicines and Health care. Strasbourg, France; 2014. p. 297-8.

29. WHO. International Pharmacopoeia, 5th edition. Monographs: dosage forms: specific monographs: artemether and lumefantrine tablets. Geneva: World Health Organization; 2014. http://apps.who.int/phint/ en/p/docf/. Accessed 12 Feb 2013.

30. European Pharmacopoeia, 8th edition. Chapter 2.2.46. Chromatographic separation techniques. European Directorate for Quality of Medicines and Health care. Strasbourg, France; 2014. p. 72-9.

31. Bozdag E, Asan U, Soyer A, Serdarasan S. Risk prioritization in failure mode and effects analysis using interval type-2 fuzzy sets. Expert Syst Appl. 2015;42:4000-15.

32. Newton PN, Green MD, Fernández FM. Impact of poor-quality medicines in the 'developing' world. Trends Pharmacol Sci. 2010;31:99-101.

33. Derringer $G$, Suich R. Simultaneous optimization of several response variables. J Qual Technol. 1980;12:214.

34. Bikbulatov ES, Stepanova IE. Harrington's desirability function for natural water quality assessment. Russ J Gen Chem. 2011;81:2694-704.

35. WHO. Global surveillance and monitoring system for substandard and falsified medicinal products. Geneva: World Health Organization; 2017. https://www.gphf.org/images/downloads/library/who-es-monitoring .pdf. Accessed 5 June 2019.

36. WHO. Guideline on packaging for pharmaceutical products. Thirty-sixth Report. Technical Report Series No 902. Annex 9. Geneva: World Health Organization; 2002. http://apps.who.int/medicinedocs/en/d/Jh3009e/. Accessed 17 Feb 2019.

37. Angeli DG, Trezza C. Quality and stability of ramipril generics/copies versus reference ramipril (Tritace): a 3-month stability comparative study. Clin Drug Investig. 2009;29:667-76.

38. Schep LJ, Slaughter RJ, Temple WA, Beasley DM. Diethylene glycol poisoning. Clin Toxicol. 2009;47:525-35.

39. Zawisza J. FDA Media Briefing on Heparin, 2008. http://www.fda.gov/ downloads/NewsEvents/Newsroom/MediaTranscripts/UCM169335.pdf. Accessed 14 Feb 2019.

40. Basco LK, Ringwald P, Manene AB, Chandenier J. False chloroquine resistance in Africa. Lancet. 1997;350:224.

41. Leslie T, Kaur H, Mohammed N, Kolaczinski K, Ord RL, Rowland M. Epidemic of Plasmodium falciparum malaria involving substandard antimalarial drugs, Pakistan, 2003. Emerg Infect Dis. 2009:15:1753-9.

42. Newton PN, McGready R, Fernandez F, Green MD, Sunjio M, Bruneton C, et al. Manslaughter by fake artesunate in Asia-will Africa be next? PLoS Med. 2006;3:e197.

43. Keoluangkhot V, Green MD, Nyadong L, Fernandez FM, Mayxay M, Newton PN. Impaired clinical response in a patient with uncomplicated falciparum malaria who received poor-quality and under-dosed intramuscular artemether. Am J Trop Med Hyg. 2008;78:552-5.

44. Kron MA. Substandard primaquine phosphate for US Peace Corps personnel. Lancet. 1996;348:1453-4.

45. Jamsen K, Duffull S, Tarning J, Lindegardh N, White N, Simpson J. Optimal designs for population pharmacokinetic studies of the partner drugs coadministered with artemisinin derivatives in patients with uncomplicated falciparum malaria. Malar J. 2012;11:143.

46. Mu J, Myers RA, Jiang H, Liu S, Ricklefs S, Waisberg M, et al. Plasmodium falciparum genome-wide scans for positive selection, recombination hot spots and resistance to anti-malarial drugs. Nat Genet. 2010;42:268-71.

47. White NJ, van Vugt M, Ezzet F. Clinical pharmacokinetics and pharmacodynamics and pharmacodynamics of artemether-lumefantrine. Clin Pharmacokinet. 1999;37:105-25.

48. WHO. World Health Organization guidelines for the treatment of malaria, 2nd edition. Geneva: World Health Organization; 2010. http://www.who. int/malaria/publications/atoz/9789241547925/en/index.html. Accessed 15 Feb 2019.

49. Alyami H, Dahmash E, Bowen J, Mohammed AR. An investigation into the effects of excipient particle size, blending techniques and processing parameters on the homogeneity and content uniformity of a blend containing low-dose model drug. PLoS ONE. 2017;12:e0178772.

50. WHO. Multisource (generic) pharmaceutical products: guidelines on registration requirements to establish interchangeability. Geneva: World 
Health Organization; 2005. https://www.who.int/medicines/services/ expertcommittees/pharmprep/QAS04_093Rev4_final.pdf. Accessed 15 Mar 2019.

51. Ambroise-Thomas P. The tragedy caused by fake antimalarial drugs. Mediterr J Hematol Infect Dis. 2012;4:e2012027.

52. International Conference on Harmonization of technical requirements for registration of pharmaceuticals for human use. ICH harmonized tripartite guideline. 2005. Q9-quality risk management. https://www.ich.org/filea
dmin/Public_Web_Site/ICH_Products/Guidelines/Quality/Q9/Step4/ Q9_Guideline.pdf. Accessed 14 Feb 2019.

\section{Publisher's Note}

Springer Nature remains neutral with regard to jurisdictional claims in published maps and institutional affiliations.
Ready to submit your research? Choose BMC and benefit from:

- fast, convenient online submission

- thorough peer review by experienced researchers in your field

- rapid publication on acceptance

- support for research data, including large and complex data types

- gold Open Access which fosters wider collaboration and increased citations

- maximum visibility for your research: over $100 \mathrm{M}$ website views per year

At BMC, research is always in progress.

Learn more biomedcentral.com/submissions 